\title{
How Consistent Contributors Inspire Individuals to Cooperate: The Role of Moral Elevation and Social Value Orientation
}

\author{
Qionghan Zhang $₫$, Yingyuan Chen $₫$, Yuan Tao, Tahir Farid $₫$ and Jianhong Ma * \\ Department of Psychology and Behavioral Sciences, Zhejiang University, 866 Yuhangtang Road, \\ Hangzhou 310058, China; joannazhang@zju.edu.cn (Q.Z.); chen.yingyuan@outlook.com (Y.C.); \\ annetao58@163.com (Y.T.); tahir_khattak@zju.edu.cn (T.F.) \\ * Correspondence: jhma@zju.edu.cn
}

\begin{abstract}
Achieving cooperation to address social dilemmas has long been a global problem. This study examined, using an environment-focused step-level public-goods-dilemma game, the effect a consistent contributor (CC) has on group cooperation, as well as the mediating role moral elevation and the moderating role social value orientation (SVO) play in this process. A total of 196 students were recruited and classified as "pro-selfs" or "pro-socials" based on their SVOs; individuals with the same SVO characterization were randomly allocated to groups of four, and then randomly assigned to the CC condition or the control condition to play 15 rounds of public-goods-dilemma games. In the CC condition, additional computer-controlled players represented the CCs. The results showed that the CC groups cooperated and earned more than the control groups did. Multi-level mediation analysis confirmed that moral elevation partially mediates the CC effect. Although the CCs had a direct impact on both pro-socials and pro-selfs, multi-level moderated-mediation analysis demonstrated that CCs influenced pro-socials directly, but affected pro-selfs' decision-making indirectly, through moral elevation. This study contributes to a better understanding of sustainability of cooperation in social dilemmas by showing that consistent cooperative behaviors are contagious, and that their effects differ based on an individuals' SVO.
\end{abstract}

Keywords: consistent contributor; cooperation; environment; moral elevation; social value orientation; step-level public goods

\section{Introduction}

Promoting cooperation in groups when individual and collective interests are in conflict has long been a prominent topic in many fields. For example, consider global environment protection; the United Nations framework convention on climate change requires all parties to the convention to limit their greenhouse-gas emissions in order to limit potentially detrimental climate change; however, obeying the convention's demands will inevitably influence the development of the economies of the countries in question [1]. As a result, instilling coordination and cooperation in regard to such conflicts continues to be a primary topic. Laboratories commonly use the "public-goods dilemma" to simulate such real-world conflicts [2,3]. In a general continuous public-goods-dilemma game, a group of individuals must decide whether to contribute a number of tokens to a public good or to keep them for their personal account. The tokens that are attributed to the public good multiply by a factor of $c(>1)$, and are distributed equally among all members of the group, regardless of their initial contributions to the public goods. A variation of this game is the step-level public-goods dilemma. In this version, the public good does not return any refund unless the contributions exceed 
a specific number. In both versions of the game, one can always benefit from avoiding contributing to the public good; however, if no one contributes, the entire team earns less than if they had to have contributed all tokens [4,5]. Therefore, contributing to the public good is usually considered to represent cooperative behavior. However, unconditional cooperation is easily capitalized on by "free-riders", and scientists have observed in iterated public-goods dilemma games that cooperation diminishes over time $[2,6]$. Therefore, structural and motivational solutions have been proposed as means of enhancing cooperation [7-9].

Structural solutions change the extrinsic social environment of a dilemma and, thus, can decrease the greed-based motivation of free-riders, as well as the fear-based motivation some may feel in regard to being exploited by others [10-12]. The representatives of the structural solution are reward and sanction systems [13], which have been proven to be efficient by numerous empirical studies on sustaining cooperation [14-16]. However, accumulating evidence has highlighted that extrinsic sanctions or rewards not only cost resources [17], but also undermine individuals' intrinsic cooperative motivation $[18,19]$. Furthermore, the sanction system is always accompanied by a risk of antisocial punishment, which easily leads to a vicious cycle of revenge $[20,21]$.

As a result, a motivational solution is believed to be more cost-effective, because it changes individuals' perceptions of their extrinsic environment [8,22]. The application of a consistent contributor (CC) as a motivational solution has previously been found to effectively promote cooperation in iterated public-goods-dilemma games [23-25]. CCs are individuals who consistently contribute to the public good, regardless of others' contributions. Both CCs and their fellow members earn more than individuals in groups without CCs [23]. One study tested engineering professionals' decision-making by asking them to imagine themselves as consultants for a sustainable infrastructure project. The results showed that projects that featured positive role models inspired positive behaviors in others [26]. Similar effects were also observed in other studies [27-29], but these have not been cited adequately, nor have they presented conclusive evidence that can be integrated to form a systematic area of research.

Considering existing findings, the present study aims to examine the role of moral elevation as a potential mechanism of the CC effect in an environment-focused step-level public-goods-dilemma game, and also seeks to investigate whether the influence of CCs affect individuals with different social orientations through the same mechanisms.

\subsection{Effect and Moral Elevation}

Many empirical studies have shown that group norms facilitate cooperation [14,30,31], and cooperative norms have also been proven to be a mediator of the CC effect [23]. While most researchers agree with these findings, they have differing opinions regarding the most suitable theory for explaining how CCs influence cooperation via perceived group norms. First, based on the "logic of appropriateness" framework [32], some scientists believe that CCs' behaviors change individuals' perceptions of the context of their groups [33], allowing the individuals to view a cooperative group norm as appropriate and, consequently, comply with it $[29,34,35]$. Second, Grant and Patil demonstrated a minority influence framework that indicated that consistent modeling can change self-interested norms [28]. This involved applying a brand-new pattern of behaviors to existing understandings of the social context, which sends a clear signal to others that such behaviors are appropriate for the team. Such "self-sacrifice" behaviors cause the minority group of CCs to be regarded as moral heroes or leaders [26,36-38], which further enhances their influence among the majority, even though the minority possess fewer resources than the majority do [39]. Third, the social-learning theory also explains the contagion of generosity from CCs to other group members [40]. For instance, Tsvetkova and Macy (2014) demonstrated that the CC effect can occur through group members imitating other key members' behaviors, which was further characterized as third-party influence in the framework of a generosity contagion [41]. 
Another explanation regarding the CC effect lies on morality. A previous study pointed out that CCs inspire generosity through the activation of moral mindset rather than through simple mutualism [24]. Researchers have argued that cooperation in social dilemmas is a kind of moral behavior [42], and that individuals are driven by moral preferences (e.g., do the right thing) to engage in such behaviors [43-47]. CCs' behaviors are generally perceived as self-sacrificial and "for the greater good," and thus, their existence functions as a silent "moral suasion" for other group members [48].

Nevertheless, few studies have discussed the role of emotions in the process of the CC effect. The classic dual-process theory suggests that two approaches work jointly in information processing and decision making: a fast, affective, and intuitive system and a slow, reason-based, deliberative system $[49,50]$. As the above-mentioned norm theories may function within the deliberative system, the emotion-related intuitive system should never be ignored. The majority of research supports the idea that emotions play a vital role in influencing individuals' decision making, and are easily activated by minorities' behaviors $[7,51,52]$. One study pointed out that a reliance on emotions may be more likely to result in a cooperative decision as compared to reliance on reasons [50]. Hence, it is well worth investigating how emotions play a part in influencing individuals' decision making after they have observed the behaviors of CCs.

CCs engage in consistent pro-social behavior and witnessing such behavior can easily initiate positive moral emotion elevation in others [28,36,53], which is usually described as a warm and uplifting feeling of being inspired as a result of witnessing others' virtuous or commendable behaviors [54]. Silvers and Haidt (2008) suggested that this experience of moral elevation is accompanied by the release in the body of oxytocin [55], a hormone that is associated with trust and pro-social behaviors [56-60]. Further, empirical experiments have found that this feeling of elevation can increase individuals' approval of pro-social behaviors, and further encourage them to engage in similar behaviors [55,56,61-64]. Considering this, we hypothesize that moral elevation mediates the relationship between the existence of CCs and fellow members' cooperation in repeated public-goods dilemma games.

Grant and Patil (2012) concluded that activation of moral elevation causes group members to feel inclined towards pro-social norms and behaviors [28]. This suggestion was later supported by the findings of a study that examined the mediating role of moral elevation on the CC effect [25]. In order to control the group norms of both conditions, the study used three computer-simulated group members and one real participant to from a group of four; however, the study consequently lacked sufficient ecological validation to explore the dynamic mechanisms that exist within a group of real participants.

Considering this, for the current study we decided to recruit groups of four participants, and simulate the CCs as experiment manipulation; therefore, the groups would be divided into two conditions: a CC condition and a control condition. CCs' behaviors have been found to bring direct benefits to group members, naturally increasing group norms in favor of cooperativeness and decreasing group members' uncooperative, fear-based motivations [23,65]. Thus, in order to focus more on the emotion-motivated mechanism of the CC effect, while excluding potential benefit-motivation, the current study adopted the step-level public-goods dilemma game [2,12]. Specifically, considering the moral nature of moral elevation, in this study the public-good paradigm was presented to participants in a moral framework relating to environment protection. The experiment design guaranteed that the payoff matrices for participants in both conditions were actually the same, regardless of the existence of CCs. Researchers have highlighted that the continuous and step-level types of public-goods-dilemma games differ from each other in terms of game theory, social interdependence theory, decision time, and social motive, and have suggested that the findings of one type of game cannot be generalized to the other [2]. In other words, even though a CC effect was tested and shown to exist in a continuous public-goods dilemma [23,24], one cannot simply say that there is also a CC effect in the step-level public-goods dilemma without testing it. Hence, in the present study we used the step-level public goods dilemma game only, as we aimed to examine the CC effect in the step-level type of public-goods-dilemma game, and particularly hoped to identify the emotional 
process (involving feelings of moral elevation) through which CCs facilitate the cooperation of other group members.

Hypothesis 1: Individuals in the CC groups will contribute more in the environment-focused step-level public-goods-dilemma game than those in the control groups will.

Hypothesis 2: Moral elevation will mediate the positive relationship between the existence of CCs and individuals' decisions in the environment-focused step-level public-goods-dilemma game.

\subsection{The Moderating Role of Social Value Orientation}

Humans are heterogenous. In particular, individuals have differing perspectives and preferences regarding self-interest and others' interests; this is known as "social value orientation" (SVO) and is a fundamental and stable predictor of decision-making $[9,66,67]$. Measurement of SVO usually classifies individuals as "pro-selfs" (i.e., individuals who strive to maximize their outcomes) or "pro-socials" (i.e., individuals who seek to maximize both their own and the group's outcomes). According to the classic "trait-consistent perspective," individuals with the same SVO should exhibit consistent behaviors across contexts $[66,68,69]$. However, this perspective is challenged by the "state-dependent perspective," which states that powerful situations such as stressful ones might produce consistent behavioral consequences, regardless of individual differences [70-72]. Thus, some researchers have proposed integrating the two theories, and suggested that trait and situation have a possible interactive effect on behaviors $[73,74]$. As a result, it is reasonable to assume that contexts involving CCs have differing impacts on individuals with different SVOs.

Two previous studies have attempted, but failed, to observe an interaction between SVO and CCs regarding contributions in a continuous public-goods dilemma [23,25]. In contrast, another study examined the influence of leaders' self-sacrifice in step-level public-goods dilemmas, and consequently found that pro-selfs are more sensitive to the existence of such leaders and posited that leaders' self-sacrifice may transform group members' motives from personal to group-oriented [38]. Although the manipulation of the self-sacrifice leaders is not identical to the CCs in the current research, this may, nevertheless, provide some new insight regarding our hypothesis.

While our current study mainly focuses on the emotional mechanism of the CC effect, we also hypothesize that the emotional process will differ for individuals with different SVOs. More specifically, we suggest that SVO moderates the relationship between CC and moral elevation (path a), as well as the relationship between moral elevation and decision-making (path b). Pro-selfs tend to maximize self-interests; for such individuals, CCs' behaviors could represent a "surprise" signal that shows them that there is an alternative strategy (rather than just focusing on their own outcomes), and that such behaviors are more appropriate in the given situation. Meanwhile, pro-socials are already willing to sacrifice their own interests to obtain a win-win situation; therefore, exposure to moral behavior will not have as strong an effect on such individuals as it will for pro-selfs. Based on the integrated trait-situation theory, we hypothesized that in our experiment the pro-socials would experience stable and high moral elevation across the two conditions, while the pro-selfs would be more emotionally sensitive to CCs and would consequently show a stronger increase in moral elevation when the two conditions are compared.

Similarly, the associations between the feelings of moral elevation and decision-making (path b) could differ between pro-socials and pro-selfs. A high level of moral elevation usually instigates a strong desire to be a better person and to engage in virtuous behaviors [61]. Such a desire may be an indicator of a transformation of motive [38]; it can drive a pro-self to re-evaluate their past behaviors and can consequently generate a tendency to cooperate in order to compensate for previous incidents of selfishness. In contrast, pro-socials always adopt a cooperative strategy and behave as "nice" people [75]; hence, moral elevation may have a weaker influence on them. 
Finally, provided one of the paths is moderated by the SVO, the indirect effect (mediation effect) of moral elevation should differ between pro-socials and pro-selfs. In other words, CCs affect individuals' decision-making in public-goods dilemmas, but the emotional mechanism (specifically, moral elevation) may differ between individuals with different SVOs.

Hypothesis 3a: Social value orientation moderates the relationship between the existence of CCs and moral elevation.

Hypothesis 3b: Social value orientation moderates the relationship between individuals' moral elevation and decisions in repeated step-level public-goods dilemmas.

Hypothesis 3c: The indirect relationship between the existence of CCs and decision-making differs depending on individuals' orientation values (pro-selfs vs pro-socials).

In summary, in our experiment involving a repeated step-level public goods-dilemma with an environment-focused framework, we initially expect to observe a CC effect. We will then seek to detect the mediating role of moral elevation in the process of the CC effect. Lastly, we will consider the moderating role of SVO, for which we expect that the effect of CC on decision-making via moral elevation will differ between pro-socials and pro-selfs (see Figure 1).

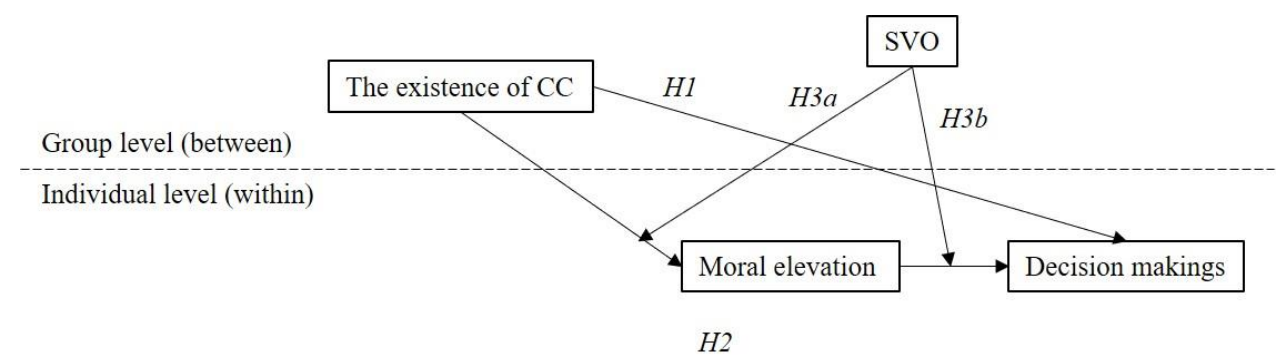

Figure 1. Conceptual model.

\section{Materials and Methods}

\subsection{Design and Participants}

The experiment comprised a $2 \times 2$ (condition: CC vs. control $\times$ SVO: pro-socials vs. pro-selfs) between-participants design. We recruited students from Zhejiang University through the university's online message board. Students were excluded if they majored in economy or if their SVOs could not be classified using the triple-dominance measure of social value scale (explained below). This resulted in a final sample of 196 undergraduate students (118 women; age range 17-24 years, $\mathrm{M}=19.45, \mathrm{SD}=1.21)$. The participants were assigned to four-person groups based on their SVOs (pro-socials: 27 groups; pro-selfs: 22 groups), and the groups were then randomly assigned either to the CC condition (pro-socials: 14 groups; pro-selfs: 11 groups) or the control condition (pro-socials: 13 groups; pro-selfs: 11 groups). The total number of 49 groups meets the general requirement of 30 groups to achieve enough power for multi-level analyses [76-78], and 40 for the multi-level structural equation modeling (MSEM) [79]. In the CC condition, participants were informed that they would interact in a five-person group. However, only four of the participants were real people; the fifth group member was a confederate manipulated by a computer program, who consistently contributed in all rounds. In the control condition, four real participants interacted in each group. All groups played 15 rounds of the step-level public-goods dilemma game. In order to simulate the real-world dilemmas in which participants face conflicts between self-interests and group-interests, and to guarantee the participants' involvement in the economic game, incentives were typically promised [13]. Specifically, participants were paid $¥ 10$ (approximately $\$ 1.70$ ) for participating, and they 
were also allowed to keep any money they gained through the public-goods dilemma (which was converted into real money at an exchange rate of 10 tokens $=¥ 1$; approximately $\$ 0.17$ ). All participants provided written informed consent. The study protocol was approved by the local ethics committee of the Department of Psychology and Behavioral Sciences at Zhejiang University, China.

\subsection{Step-Level Public Goods Dilemma}

The step-level public goods dilemma was adapted from a previous study [80], and was presented using an environment-focused scenario [81]. Participants were asked to imagine themselves as representatives of a company, and that they were trying to form an environmental-protection-focused corporation with the other members in their groups. At the beginning of each trial, participants were given 10 tokens, and were asked to decide whether they would contribute all of the tokens to their individual accounts or contribute them to an environment account. If at least $X$ persons (the control group: $X=2$; the $C C$ group: $X=3$ ) contributed to the environment account, the environmental protection corporation would be successfully established, and all participants would receive a refund (which was calculated using the following equation; $\mathrm{n}=$ number of participants who contributed to the environment account). However, if an insufficient number of persons contributed to the environment account, the participants would lose the money they contributed to the environment account. The final outcome comprised the refund from the environment account and the tokens in the individual account (see Table 1). Each participant was randomly assigned a number as their identity, meaning they played the step-level public goods dilemma anonymously over the 15 rounds.

$$
\text { Refund from the environment account }= \begin{cases}0 & \mathrm{n}<\mathrm{X} \\ 12+(\mathrm{n}-\mathrm{X}) * 10 * 0.6 & \mathrm{n} \geq \mathrm{X}\end{cases}
$$

Table 1. The payoff matrices of (A) the control condition (four-persons group) and (B) the consistent contributor (CC) condition (five-person group).

\begin{tabular}{|c|c|c|c|c|c|c|c|}
\hline \multirow[t]{2}{*}{ A. } & \multicolumn{7}{|c|}{ The number of PPs in the group choosing the environment account } \\
\hline & & $0 \mathrm{PP}$ & $1 \mathrm{PP}$ & 2 PPs & 3 PPs & 4 PPs & \\
\hline Did you choose & Yes & / & 0 & 12 & 18 & 24 & \\
\hline the environment account? & No & 10 & 10 & 22 & 28 & / & \\
\hline \multirow[t]{2}{*}{ B. } & \multicolumn{7}{|c|}{ The number of PPs in the group choosing the environment account } \\
\hline & & $0 \mathrm{PP}$ & $1 \mathrm{PP}$ & 2 PPs & 3 PPs & 4 PPs & 5 PPs \\
\hline Did you choose & Yes & / & 0 & 0 & 12 & 18 & 24 \\
\hline the environment account? & No & 10 & 10 & 10 & 22 & 28 & / \\
\hline
\end{tabular}

Note. $\mathrm{CC}=$ Consistent contributor; $\mathrm{PP}=$ Participant.

CCs were operationally defined as group members who consistently contribute to the public account (i.e., the environment account) [23]. In this study, the CCs were programmed to choose the environment account across all 15 rounds. In order to ensure that the participants noticed the behaviors of the CCs, in each round we asked the participants to predict every other group member's choice using the following question: "What choice do you think Player $\mathrm{X}$ will make in the next round?" If the existence of a CC was noticed, the payoff matrix of the CC condition was actually equal to the payoff matrix of the control condition.

\subsection{Measures}

Participants' SVOs were measured using the well-validated nine-item triple-dominance measure of the social value scale $[23,82,83]$, which has been proven to be reliable and valid among the Chinese population [84]. For each item, respondents are asked to choose one of three different options, which present outcomes pertaining to the participant himself/herself and an anonymous other 
person. The three options are classified into: (1) the pro-social option, which represents the most beneficial, and most fair, joint outcomes for the participant and the other (e.g., 480 points for one's self and 480 points for the other); (2) the individualistic option, which represents the most beneficial outcome for the participant of the three options (e.g., 540 points for one's self and 280 points for the other); and (3) the competitive option, which represents the most beneficial outcome for the participants when compared to the other's outcome (e.g., 480 points for one's self and 80 points for the other). Respondents are classified into one of the three orientations if they chose six or more options (of the nine items) pertaining to that orientation. Following Haesevoets, Folmer, and Van Hiel (2015), we aggregated the competitors and individualists into the new category of "pro-selfs," because both showed a preference for maximizing their own outcomes [85]. Previous literature has indicated that only a small minority cannot make consistent choices in the scale $(15 \%$ in the research of Declerck, Boone, and Kiyonari [59]). In order to test our hypotheses regarding SVO, only students who could be classified as pro-socials or pro-selfs were invited to participate in the larger experiment.

Moral elevation was measured using a nine-item scale we developed by examining the literature and instruments. A group of Chinese researchers (2014) integrated different elevation scales developed in Western countries [86,87], and proposed a 25-item scale that was then proven to be reliable and suitable for measuring the moral elevation of Chinese college students, with a Cronbach's alpha value of 0.93 [88]. To adapt it to the current study, we refined the scale using the three dimensions proposed by Schnall et al. (2010), namely emotional components, views of humanity, and desire to be a better person [61]. Emotional components were assessed by asking participants to rate the level to which they felt the following emotions after the public-goods-dilemma game: moved, uplifted, admiration, and a warm feeling in the chest. Meanwhile, views of humanity were measured in the same manner after the public-goods dilemma using the following items: "optimistic about humanity," "there is still some good in the world," and "people are really good." Finally, desire to be a better person was also assessed after the public-goods dilemma using two items: "I want to help others" and "I want to become a better person." All items were rated using a nine-point scale $(1=$ "did not feel at all," 9 = "felt very strongly"). The overall Cronbach's alpha value for the items was 0.94 .

\subsection{Procedure}

Potential participants completed the triple-dominance measure of social value scale upon enrolling for the experiment. Of these, students who did not major in economy and who could be classified as pro-socials or pro-selfs were then invited to perform the experiment. Upon arrival at the laboratory, all participants were provided with informed consent forms to read and sign. They were then seated at separate tables in a large computer room, and were forbidden to communicate with each other for the entire experiment. Subsequently, they were provided with instruction booklets explaining the rules of the step-level games, consistent with their assigned conditions, and were asked to complete some questions to confirm their understanding of the rules.

After all questions had been completed correctly, the experiment began. The experiment was developed using a software called "z-Tree" [89]. During the experiment, an environment-focused step-level public-goods dilemma game was introduced, and participants were asked to play 15 rounds of the game in groups of four (control condition) or five (CC condition). In each round, they were asked to decide whether they would like to contribute their tokens to their individual accounts or to the environment account, and also to indicate their predictions of the other group members' choices. After 15 rounds, they completed questionnaires and indicated their feelings of moral elevation. As a manipulation check, participants were asked to rate the following question using a seven-point scale ( 1 = "strongly disagree," 7 = "strongly agree"): "There was someone in my group who always put their tokens in the environment account." [23] After all the questionnaires had been completed, participants were thanked for their participation and dismissed. 


\subsection{Statistical Analyses}

The present experiment used a $t$-test and a paired $t$-test to confirm the successful manipulation of CC. Since four participants (within level: individual level) were nested within each group (between level: group level), to test the CC effect (H1), we performed two-level multi-level modeling (MLM) analyses using the HLM 7 software (Scientific Software International Inc., Lincolnwood, IL, USA). Specifically, we estimated a multi-level model that specified the effect the existence of a CC (between level predictor) had on participants' decision-making and profit (within level-dependent variables).

The multi-level mediation and moderated mediation models were conducted using the Mplus 7.4 software [90]. To test the multi-level mediation effect for $\mathrm{H} 2$ and the multi-level moderated mediation effect for H3, we used MSEM [91,92]. MSEM is believed to have several advantages over traditional MLM regarding assessing mediation effects using nested structured data [91,93]. MLM usually biases between effects, combining the between-subject and within-subject effects of within variables. This results in conflating the estimation, and fails to include the observed and measurement error in the model estimation. Meanwhile, MSEM corrects the sampling error, separates the between and within effects for model estimation, and includes traditional latent variables for measurement error [91]. The relationships between the independent variable, the mediator, the moderator, and the dependent variable on the different levels are illustrated in Figure 2.

A.

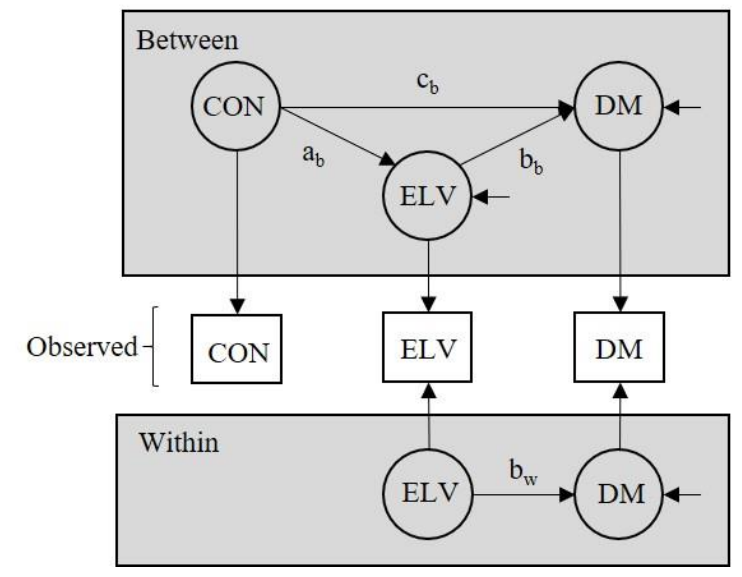

B.

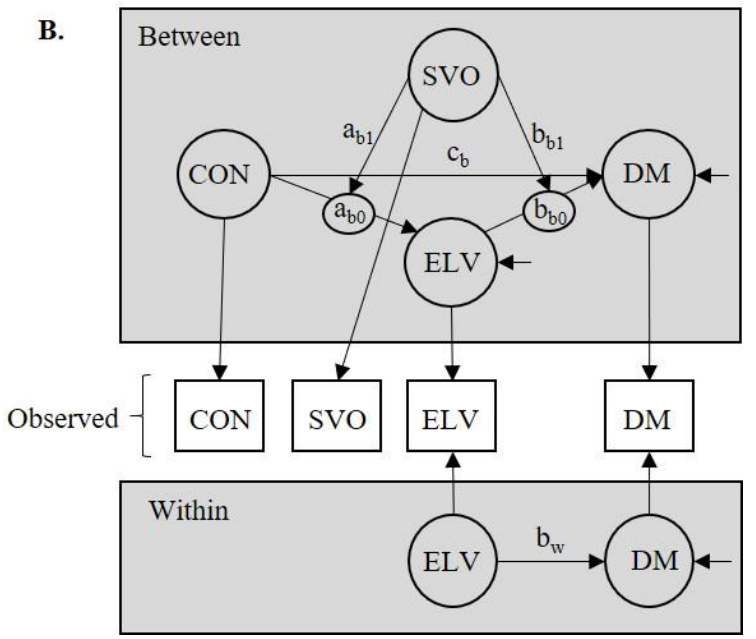

Figure 2. Multi-level structural equation model showing (A) a 2-1-1 multi-level mediation model between condition (CON), elevation (ELV), and decision-making (DM); and (B) a 2-1-1 multi-level moderated mediation model between condition (CON), elevation (ELV), social value orientation (SVO), and decision-making (DM). The arrows extending from circles indicate random effects.

The most commonly used method for testing mediation is the casual-steps approach [94]; however, this method has been criticized for its lack of power and the fact that it is not based on quantification $[95,96]$. Therefore, the Sobel test is used as a supplemental method, which mitigates the bias by examining the significance of $a^{*} b[97,98]$. However, the Sobel test assumes $a^{*} b$ to be normally distributed when it is actually asymmetric. As a result, bootstrapping is recommended as an alternative method, and has already been implemented in some software, such as in Mplus and R [95]. Several simulation studies have highlighted the power and efficiency of bootstrapping over the Sobel test and the casual steps approach regarding testing mediating and moderating effects, and have suggested that users only report the results of bootstrapping instead of the results for all three methods [96,99]. Unfortunately, bootstrapping is not available when running multi-level analyses in Mplus and, therefore, we used the open-source software $\mathrm{R}$ (available at http://www.r-project.org/) (R Foundation for Statistical Computing: Vienna, Austria) 
to run 20,000 Monte Carlo replications [100-102], which conducted parameter bootstrapping in order to obtain a percentile confidence interval $(\mathrm{CI})$ around the observed indirect effect.

\section{Results}

\subsection{Manipulation Checks of the Consistent Contributors}

Participants in the CC groups responded more positively to the question "there was someone in my group who always put their tokens in the environment account" $(\mathrm{M}=5.55, \mathrm{SD}=1.62)$ than did participants in the control groups $(\mathrm{M}=4.09, \mathrm{SD}=1.81, t(194)=-5.95, p<0.001)$, whic proved the success of the CC manipulation. Furthermore, we compared participants' predictions of the other group members' choices for each round (see Figure 3), and observed that from round 6, participants had higher contribution expectations of the CCs than of the other group members. Therefore, we compared the average estimation for the $\mathrm{CCs}(\mathrm{M}=0.82, \mathrm{SD}=0.22)$ and the other group members $(\mathrm{M}=0.71$, $\mathrm{SD}=0.20$ ) in the CC groups from round 6 to round 15, and the results showed a significant difference $(t(99)=-4.49, p<0.001)$. We also compared the average prediction for the CC $(\mathrm{M}=0.82$, $\mathrm{SD}=0.22)$ and the predictions for the group members in the control groups $(\mathrm{M}=0.57, \mathrm{SD}=0.19)$ from rounds 6 to 15, and the difference was also significant $(t(194)=-8.32, p<0.001)$. As a result, we found that we had successfully manipulated the existence of the CCs, and the participants began to recognize the CCs' behaviors at, on average, round 6. Following Weber and Murnighan (2008) [23], we only included participants' decisions from round 6 to 15 for further analyses, because these were the periods when the CCs actually had effects on the individuals. We also compared the first round of contribution across the two conditions (see Figure 4), finding that the difference in contribution rates between the two conditions was not significant (control groups: $\mathrm{M}=73 \%, \mathrm{SD}=0.45$; CC groups: $\mathrm{M}=75 \%, \mathrm{SD}=0.44 ; t(194)=-0.331, p>0.05)$; this showed that the participants' initial expectations of the games did not have significant differences across the two conditions.

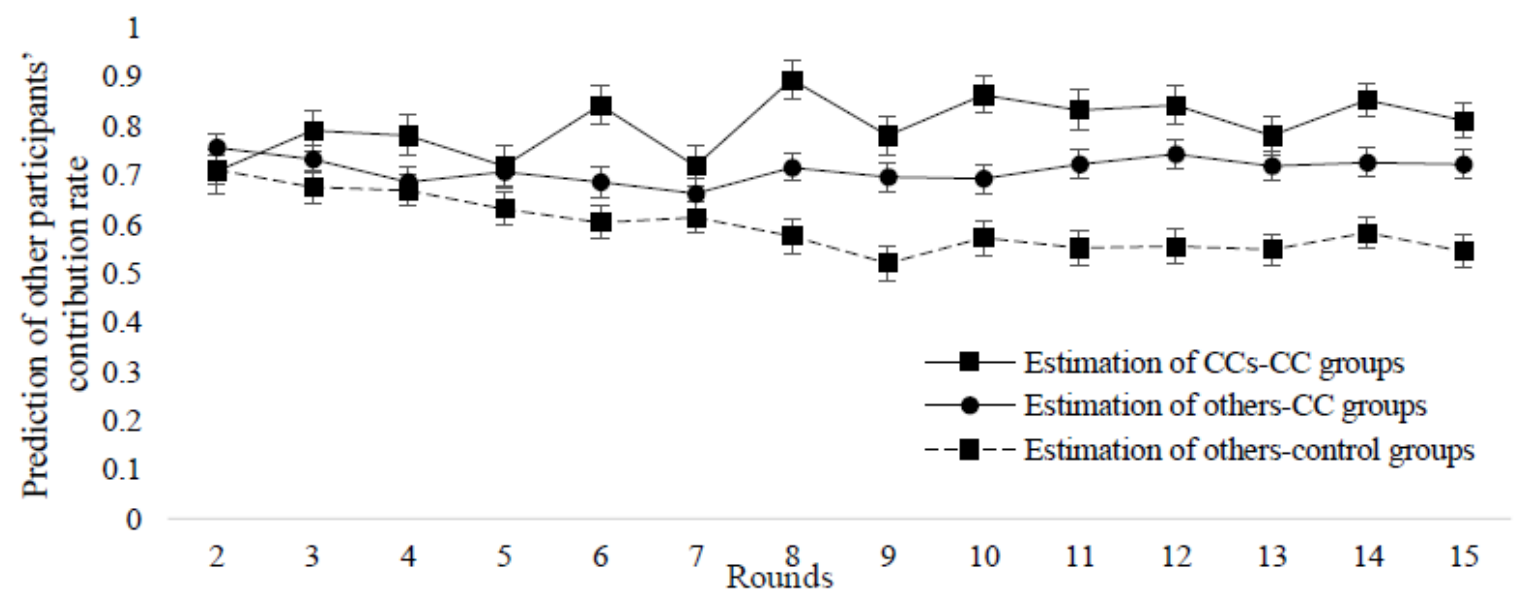

Figure 3. Differing predictions of the behavior of the CCs and other group members in the CC groups, and the differing predictions of the members of the CC groups and the control groups. 


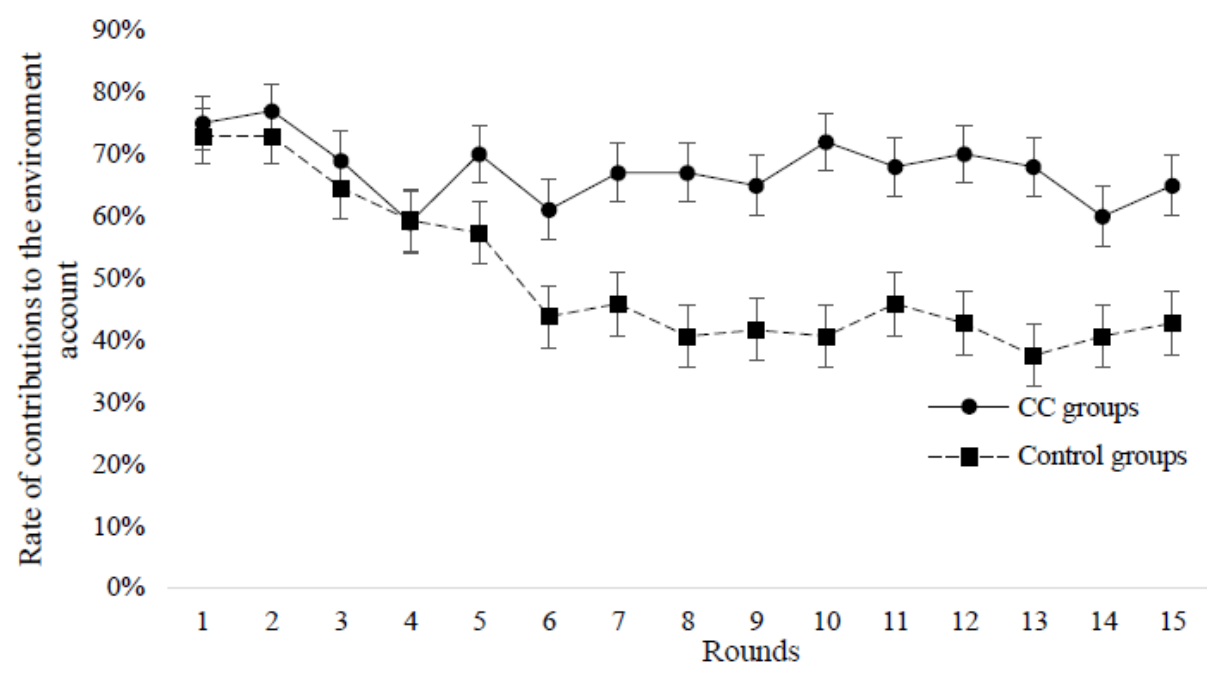

Figure 4. The CC groups and control groups' rate of contributions to the environment account over the 15 rounds.

\subsection{Effect in Step-Level Public-Goods Dilemma}

Multi-level analyses indicated that members of the CC groups contributed significantly more to the environment account during the final 10 rounds $(M=6.63, S D=2.64)$ than did members of the control group $(\mathrm{M}=4.22, \mathrm{SD}=2.48 ; t(47)=5.90, p<0.001$; see Figure 4). The experiment design guaranteed that the existence of the $\mathrm{CC}$ did not bring any economic benefit for the CC group members compared to the control group members; therefore, we were able to compare the profits of the participants in both groups, and found that participants in the CC groups $(M=194.02, S D=59.88)$ also earned more over the last 10 rounds than did the participants in the control groups $(M=145.94$, $\mathrm{SD}=35.32 ; t(47)=3.70, p<0.001)$. Moreover, the participants in the $\mathrm{CC}$ groups $(\mathrm{M}=6.77, \mathrm{SD}=1.73)$ reported higher moral elevation than did the participants in the control groups $(M=5.65, S D=1.71$; $t(47)=3.68, p<0.001)$.

\subsection{The Mediating Role of Moral Elevation}

To test H3, we examined a 2-1-1 model in which the relationship between condition (between-level) and participants' decision-making (within-level) was mediated by moral elevation (within-level; see Table 2). The results revealed a significant indirect effect (1.94), with a 95\% confidence interval (CI) that did not contain zero [0.73, 3.22]; this supported the mediation hypothesis $(\mathrm{H} 2)$. Further, the path $\mathrm{c}_{\mathrm{b}}$ remained significant after the indirect effect was included in the model, and showed that the relationship between CC and decision making was partially mediated.

Table 2. 2-1-1 multi-level mediation models predicting individuals' decision-making in the public-goods dilemmas.

\begin{tabular}{llll}
\hline & Estimate & SE & $95 \%$ CI \\
\hline Between level & & & \\
Intercept & $5.65^{* * *}$ & 0.24 & {$[-5.63,-5.49]$} \\
Path $\mathrm{a}_{\mathrm{b}}$ & $1.11^{* *}$ & 0.35 & {$[0.43,1.79]$} \\
Path $\mathrm{b}_{\mathrm{b}}$ & $1.33^{* * *}$ & 0.11 & {$[1.13,1.54]$} \\
Path $\mathrm{c}_{\mathrm{b}}$ & $0.41^{* * *}$ & 0.07 & {$[0.28,0.54]$} \\
Residual variance ELV & $0.58^{* * *}$ & 0.16 & {$[0.26,0.90]$} \\
Residual variance DM & $0.28^{* * *}$ & 0.04 & {$[0.19,0.36]$} \\
Within level & & & \\
Path $\mathrm{b}_{\mathrm{w}}$ & $0.51^{* * *}$ & 0.07 & {$[0.20,0.63]$} \\
Residual variance DM & $5.14^{* * *}$ & 0.58 & {$[4.00,6.28]$} \\
Indirect effect & $1.94^{* *}$ & 0.61 & {$[0.73,3.22]^{a}$} \\
\hline
\end{tabular}

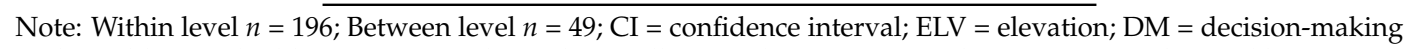
in the public-goods-dilemma game. The paths are illustrated in Figure 2. ${ }^{a}$ The $95 \%$ CI was obtained by running 20,000 Monte Carlo replications; ${ }^{*} p<0.05,{ }^{* *} p<0.01,{ }^{* * *} p<0.001$. 


\subsection{The Moderated Mediation Effects}

Multi-level analyses showed a significant main effect of SVO on decision-making, with the pro-socials $(\mathrm{M}=5.94, \mathrm{SD}=2.89)$ contributing more to the environment account than the pro-selfs did $(\mathrm{M}=4.85, \mathrm{SD}=2.65 ; t(45)=2.84, p<0.01)$. However, the interaction of SVO and condition was not significant $(t(45)=-1.94, p>0.05)$.

We then created two separate models using moderated mediation MSEM analyses (see Table 3). Model 1 examined the moderating role of SVO in the relationship between the existence of CC and moral elevation (path $\mathrm{a}_{\mathrm{b} 0}$ ), and Model 2 examined the moderating role of SVO in the relationship between moral elevation and individuals' decision-making in the final 10 rounds of the repeated step-level public-goods dilemma game (path $b_{\mathrm{b} 0}$ ). The result showed that SVO moderates path $\mathrm{a}_{\mathrm{b} 0}$, and the interaction between SVO and CC was significant, with a 95\% CI of $[-2.04,-0.22]$; this supported H3a (see Figure 5). However, SVO did not moderate path $b_{b 0}$, and the interaction between SVO and moral elevation was not significant, with a $95 \%$ CI of $[-0.12,0.04]$, which meant $\mathrm{H} 3 \mathrm{~b}$ was not true. We further interpreted the conditional indirect effect of CC on decision-making via moral elevation, with SVO moderating the relationship between CC and moral elevation. The result showed that the existence of a CC in the group was positively related, via moral elevation, to participants' decision-making in the step-level public-goods dilemma, but only among pro-self groups. Specifically, for pro-selfs, the conditional indirect effect of CC influence on decisions via moral elevation was 0.24 , with a $95 \%$ CI of $[0.06,0.46]$ (i.e., not containing zero). Therefore, the mediation effect for pro-selfs was significant. In contrast, for pro-socials the conditional indirect effect of CC influence on decisions via moral elevation was non-significant, with an estimate of 0.08 and a $95 \% \mathrm{CI}$ of $[-0.08,0.29]$ (i.e., containing zero). The difference between the two conditional indirect effects was tested to be significant, with a $95 \%$ CI of $[-0.35,-0.02]$, which supported H3c.

Table 3. 2-1-1 multi-level moderated mediation models predicting participants' decision-making in the public-goods-dilemma game.

\begin{tabular}{|c|c|c|c|c|c|c|c|}
\hline & \multicolumn{3}{|c|}{ Model 1} & \multicolumn{3}{|c|}{ Model 2} \\
\hline & & Estimate & $\mathrm{SE}$ & $95 \% \mathrm{CI}$ & Estimate & SE & $95 \% \mathrm{CI}$ \\
\hline \multicolumn{8}{|c|}{ Between level } \\
\hline \multicolumn{2}{|c|}{ Intercept } & $3.45^{* * *}$ & 0.15 & {$[3.16,3.75]$} & -0.35 & 0.29 & {$[-0.91,0.21]$} \\
\hline Path $a_{b}$ & $\begin{array}{l}\text { Path } a_{b 0} \\
\text { Path } a_{b 1}\end{array}$ & $\begin{array}{l}1.72 * * * \\
-1.13 *\end{array}$ & $\begin{array}{l}0.40 \\
0.46\end{array}$ & $\begin{array}{c}{[0.94,2.51]} \\
{[-2.04,-0.22]}\end{array}$ & $1.11^{* * *}$ & 0.30 & {$[0.52,1.70]$} \\
\hline Path $b_{b}$ & $\begin{array}{l}\text { Path } b_{\mathrm{b} 0} \\
\text { Path } b_{\mathrm{b} 1}\end{array}$ & $0.14^{* *}$ & 0.05 & {$[0.04,0.23]$} & $\begin{array}{c}0.43^{* * *} \\
-0.04\end{array}$ & $\begin{array}{l}0.04 \\
0.04\end{array}$ & $\begin{array}{c}{[0.37,0.50]} \\
{[-0.12,0.04]}\end{array}$ \\
\hline \multicolumn{2}{|c|}{ Path $c_{b}$} & $2.24^{* * *}$ & 0.39 & {$[1.48,3.00]$} & $1.08^{* * *}$ & 0.09 & {$[0.91,1.25]$} \\
\hline \multicolumn{2}{|c|}{ Residual variance ELV } & $0.97^{* * *}$ & 0.22 & {$[0.53,1.40]$} & $0.57^{* * *}$ & 0.18 & {$[0.22,0.93]$} \\
\hline \multicolumn{2}{|c|}{$\begin{array}{c}\text { Residual variance DM } \\
\text { Within level }\end{array}$} & 0.76 & 0.73 & {$[-0.67,2.19]$} & $0.71^{* * *}$ & 0.05 & {$[0.62,0.81]$} \\
\hline \multicolumn{2}{|c|}{ Path $b_{\mathrm{w}}$} & $0.45^{* * *}$ & 0.11 & {$[0.23,0.66]$} & $0.43^{* * *}$ & 0.04 & {$[0.37,0.50]$} \\
\hline \multicolumn{2}{|c|}{ Residual variance DM } & $5.11^{* * *}$ & 0.51 & {$[4.10,6.11]$} & $5.11^{* * *}$ & 0.57 & {$[4.00,6.22]$} \\
\hline \multicolumn{2}{|c|}{$\begin{array}{l}\text { Conditional indirect effect } \\
\qquad(\mathrm{SVO}=\text { pro-self })\end{array}$} & $0.24^{* *}$ & 0.08 & {$[0.06,0.46]^{a}$} & $0.48^{* *}$ & 0.14 & {$[0.22,0.76]^{a}$} \\
\hline \multicolumn{2}{|c|}{$\begin{array}{l}\text { Conditional indirect effect } \\
\quad(\mathrm{SVO}=\text { pro-social })\end{array}$} & 0.08 & 0.06 & {$[-0.08,0.29]^{a}$} & $0.44^{* *}$ & 0.13 & {$[0.20,0.72]^{a}$} \\
\hline \multicolumn{2}{|c|}{ Difference between two conditions } & $-0.15^{*}$ & 0.07 & {$[-0.35,-0.02]^{a}$} & -0.04 & 0.05 & {$[-0.14,0.05]^{a}$} \\
\hline
\end{tabular}

Note. Within level $n=196$; Between level $n=49 ; \mathrm{CI}=$ confidence interval; ELV = elevation; DM = decision-making in the public-goods dilemma; $\mathrm{SVO}=$ social value orientation (code: pro-self $=0$, pro-social $=1$ ). Model 1 examines the moderating role of SVO in the relationship between CC and ELV; Model 2 examines the moderating role of SVO in the relationship between ELV and DM. The paths are shown in Figure 2. ${ }^{a}$ The $95 \% \mathrm{CI}$ was obtained by running 20,000 Monte Carlo replications; ${ }^{*} p<0.05,{ }^{* *} p<0.01,{ }^{* * *} p<0.001$. 


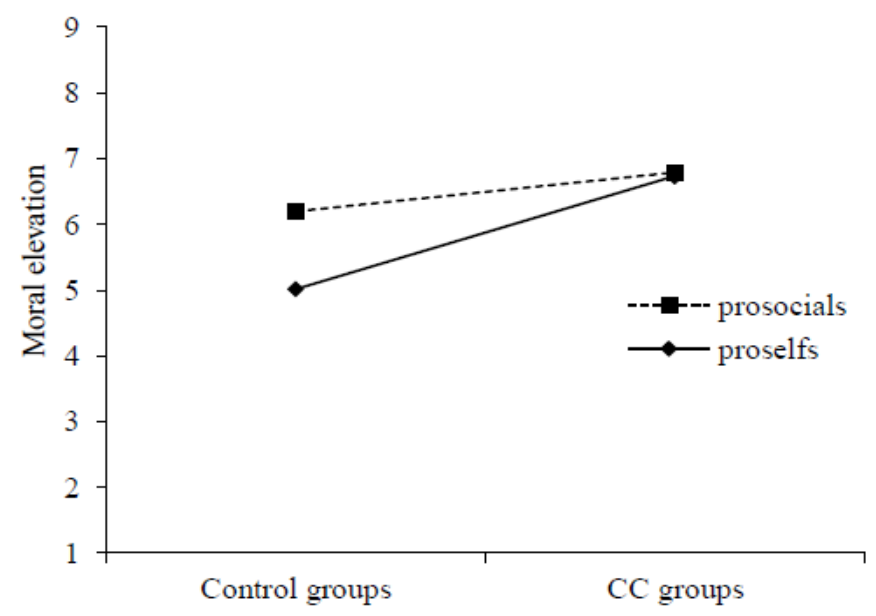

Figure 5. The interaction effect between social value orientation and the existence of CC on feelings of elevation.

\section{Discussion}

Achieving and maintaining cooperation in groups has always been a global problem, because it requires personal interests to compromise in favor of collective interests. Consider the field of environment protection as an example; the agreements obtained in real-life always fail to satisfy the requirements for environmental sustainability [34]. In the present article, we examined the CC effect in an environment-focused step-level public-goods-dilemma game. In accordance with previous studies [23-25], our results showed that the introduction of CCs as a motivational solution can effectively sustain cooperation in the domain of environment protection. Moreover, participants who responded to CCs and cooperated more in the dilemma game not only avoided any risk of exploitation by free-riders, but also benefited from their behaviors (creating a win-win situation), which is a clear signal for future cooperation in the long term. In addition, we observed that the feeling of moral elevation partially mediates the relationship between the existence of CCs and individuals' decision-making in the public-goods-dilemma game. Further, multi-level moderated mediation analysis showed that, although the CCs had a positive effect on the decisions of both pro-socials and pro-selfs, the underlying emotional mechanisms differed. Specifically, pro-socials' increased contributions were motivated directly by the CCs, but the pro-selfs' decision-making was influenced indirectly by CCs through their feelings of moral elevation. Our findings clearly illustrate a model of how eco-friendly cooperative decision-making is driven by the existence of CCs, and highlights the role of moral elevation and SVO in this model.

The current study contributes to creating a general understanding of the mechanism underlying the CC effect by including moral elevation in the model. The results demonstrated that our participants perceived the consistent contribution behaviors as morally good or virtuous, and these feelings were so strong that they caused a high level of moral elevation, which is in accordance with the findings of previous research [25]. The activation of elevation does not require the contribution of a large number of persons, merely a single person's virtuous act. This also provides a supplementary explanation of the norm-based minority influence theory regarding the CC effect, in that it describes how the generous behaviors of a minority group can be contagious, eliciting moral elevation in others. It is also possible that norm transformations observed and reported in previous literature were caused by the activation of elevation [38]; this should be explicitly considered in future studies. Moreover, our findings agree with various other findings regarding moral elevation causing altruistic behavior [55,61-64]. In short, the mere exposure to a cooperative environment involving CCs may directly cause some individuals to cooperate; meanwhile, other individuals are willing to mimic CCs' pro-social environment-related behaviors if their morals are elevated. 
On the basis of the trait-situation integrated theory, we examined the moderating role of SVO in the CC effect, and found that the existence of CCs and SVO had no interactive effect on individuals' environmental decision-making. This result is consistent with those of several previous studies that have used the continuous public-goods dilemma $[23,25]$. When we further considered the mediating role of moral elevation in the process of the CC effect, we found that SVO moderates the relationship between the presence of CCs and moral elevation, but not the relationship between moral elevation and environmental decision-making.

To be specific, pro-selfs are more sensitive to CCs' behaviors than pro-socials are, in that they show higher increased elevation than pro-socials do. This pattern is consistent with that of a previous study that discovered that pro-selfs exhibit more cooperation in step-level public-goods dilemmas when self-sacrifice leaders are present [38]. The authors explained this phenomenon using the transformation assumption: that a charismatic leader can lead others to think and behave in a manner that transcends self-interest $[103,104]$. Although the current study found a direct effect of CCs on pro-socials and pro-selfs' decisions, such a pattern was observed in regard to how moral elevation is inspired by CCs' behaviors. Thus, our findings may provide a new perspective to this transformation theory, suggesting that positive emotion, such as moral elevation, plays a role in this regard.

The fact that SVO did not moderate the relationship between moral elevation and decision-making suggests that moral elevation induces a stable and general prediction of prosocial decisions, regardless of one's SVO. This accords with previous findings, that moral elevation leads to altruistic behavior [55,61-64], and also presents us with a new idea regarding environmental protection inducing feelings of moral elevation in individuals. The application of these findings can vary, from advertisements for national environment protection to environment-related decisions inside communities. The introduction or advertisement of consistent eco-friendly behaviors in minorities could effectively elicit moral elevation in other individuals and further enhance their tendency to make pro-environment decisions. When it comes to education regarding environmental protection, much effort has been invested in the dissemination of injunctive norms [105]. Injunctive norms tell us what others expect us to do, whereas descriptive norms (what most people do) are normally considered more efficient in promoting environmental behaviors [106]. Our findings provide an alternative method by introducing role models who consistently contribute to environment protection. These model examples are more likely to evoke positive emotions among students such as moral elevation which further leads to people voluntarily following the behaviors from these moral examples.

With regard to the mediating effect of moral elevation on the CC effect, the findings indicated that elevation actually mediates the relationship between CCs and decision-making among pro-selfs, but not among pro-socials. In fact, simple exposure to CCs is enough for pro-socials to follow and engage in pro-social or eco-friendly decision-making. This is probably due to pro-socials' initial high tendencies to maximize the joint interests of the group and themselves. A group of pro-socials is already highly cooperative, and the introduction of a CC will not generate a great impact. However, for the pro-selfs, who seek to maximize their own profits, the generous behaviors of CCs actually contravene their general understanding of appropriate behaviors in such social dilemmas. Therefore, the consistency of the CCs instigates a higher level of moral elevation in pro-selfs than in pro-socials. Such highly activated elevation further motivates pro-selfs to cooperate more in public-goods dilemmas. This fact was highlighted in that, although CCs' behaviors are generally contagious, the mechanism of contagion actually differed between our participants' SVO types. This result supports the trait-situation theory: that individuals with different traits may have different responses to exposure to consistent pro-social minorities.

Even though the current study focused on the personal traits of SVOs, we believe moral preference could be another important trait influencing CCs' effects, which is worth further investigation. Our observation of the highly activated moral elevation of participants in reaction to CCs' behaviors implies that the $\mathrm{CCs}^{\prime}$ behaviors were perceived as moral behaviors, and also provides further evidence for previous studies that augured contributions to the public goods dilemma as moral behaviors $[24,42]$. 
The majority of studies have illustrated the predictive role of moral preferences in moral behaviors; that people engaged in behaviors they believed to be morally right [43-47]. Therefore, a study targeting the relationship between individuals' moral preference decisions in reaction to the CCs' behaviors merits further consideration.

Additionally, the current study contributed to highlighting a relatively novel and practical multi-level modeling technique by adopting MSEM analyses, rather than MLM, for assessing multi-level mediation and moderated mediation effects. MSEM has several advantages over MLM, as it can address several limitations of MLM, as mentioned earlier. The adoption of this advanced method helps in regard to the promotion and generalization of results.

Concerning the novelty of the study, we examined the effect of consistent contributors in sustaining cooperation in an environment-focused step-level public-goods-dilemma. Most of the previous research only examined the CC effect in a continuous step-level public-goods dilemma game $[23,24]$, and these results were suggested to be unable to generalize from the continuous type of public-goods dilemma to the step-level type [2]. Therefore, our current findings contributed to the understanding of the CC effect in such contexts and highlighted the generalization of CC effect in all types of public-goods dilemma. Furthermore, we have discussed the mediating role of moral elevation in the CC effect, while only a few studies have ever paid attention to this important emotion $[25,28]$. Finally, we successfully examined the role of SVO in the CC effect. We made an innovative proposal that SVO may modulate the mediating process of moral elevation in the CC effect, and the results supported that SVO moderated the relationship between CCs and moral elevation. The cooperation that we discussed in the current study is related to environmental protection, in which maintaining cooperation has been of great significance.

Some limitations to this study should be mentioned. First, the group sizes and payoff matrices of the control groups and the CC groups were different. This is because the consistent contributing behaviors of the CCs actually reduced the provision capability of the CC groups by one person. Consequently, adding one person to the CC groups' provision points guaranteed that the provision points for the real participants were the same for each condition once the CCs were perceived. The data showed that the CCs' existence was noticed from approximately round 6 and, thus, we only included the data for the last 10 rounds in our analyses. In addition, the participants' first-round contributions across the two conditions showed statistically nonsignificant differences, which meant that the structural differences as a result of the group size and the payoff matrix did not have a strong impact on participants' initial decision-making. However, it is clear that not all participants realized the existence of the CCs in round 6 and they were not also $100 \%$ sure of the CCs' future choices. As a result, an improved design for the step-level public-goods dilemma that involves introducing a CC into a group without changing the original payoff matrix should be employed in future studies.

Second, our assessment of positive moral elevation lacked diversity. Moral elevation can cause a release of the hormone oxytocin, which could be the physiological mechanism of moral elevation that increases an individuals' cooperative tendency [57-60]. Moral elevation has also been suggested to be accompanied by other physiological changes, such as a feeling of "warmth" in one's chest, a lump in one's throat, elevated heart rate, and relaxed muscles [63]. The employment of physiological measures such as heart rate, blood pressure, and skin conductance response to assess the intensity of elevation may help to extend our understanding of moral elevation and its role in the CC effect.

Third, the current research examined a motivation-based solution for inducing cooperation in the framework of environment protection using the step-level public-goods dilemma (also known as the "give-some dilemma"). Another commonly used type of social dilemma relating to the environment is the "common-pool dilemma" (also known as the "take-some dilemma"). In the common-pool dilemma, individuals must decide how many resources they would like to harvest from a common pool, while restraining their desire to exploit all of the resources in order to allow resource regeneration $[107,108]$. The framing of the two games can have a different impact on decision-making [109]; however, 
the importance of cooperation maintenance does not change. It would be of interest for future research to consider the CC effect in the common pool dilemma.

Our findings have implications regarding means of sustaining cooperation in conflicting situations, especially regarding environmental-protection issues. By displaying to pro-selfs the consistent modeling behaviors of minorities, the pro-selfs may feel elevated and feel a desire to engage in pro-social behaviors; meanwhile, pro-socials can mimic such generous behaviors directly.

Author Contributions: Conceptualization, Q.Z., Y.T. and J.M.; Data curation, Q.Z., Y.C. and Y.T.; Formal Analysis, Q.Z. and Y.C.; Funding Acquisition, J.M.; Investigation, Q.Z., Y.C. and Y.T.; Methodology, Q.Z., Y.T. and J.M.; Project Administration, Q.Z.; Resources, J.M.; Software, Q.Z. and Y.C.; Supervision, J.M.; Validation, Q.Z., Y.C., T.F. and J.M.; Visualization, Q.Z. and T.F.; Writing-Original Draft, Q.Z.; Writing-Review and Editing, Q.Z., Y.C., Y.T., T.F. and J.M.

Funding: This research was funded by the National Natural Science Foundation of China, grant number [71871201] and [71371166]. The APC was funded by the National Natural Science Foundation of China, grant number [71371166].

Conflicts of Interest: The authors declare no conflict of interest.

\section{References}

1. UNFCCC. Fifth Assessment Report of the Intergovernmental Panel on Climate Change; UNFCCC: Geneva, Switzerland, 2014.

2. Abele, S.; Stasser, G.; Chartier, C. Conflict and Coordination in the Provision of Public Goods: A Conceptual Analysis of Continuous and Step-Level Games. Personal. Soc. Psychol. Rev. 2010, 14, 385-401. [CrossRef] [PubMed]

3. Kawagoe, T.; Matsubae, T.; Takizawa, H. Quantal Response Equilibria in a Generalized Volunteer's Dilemma and Step-Level Public Goods Games with Binary Decision. Evol. Inst. Econ. Rev. 2018, 15, 11-23. [CrossRef]

4. $\quad$ Dawes, R.M. Social Dilemmas. Annu. Rev. Psychol. 1980, 31, 169-193. [CrossRef]

5. Estrela, S.; Libby, E.; Van Cleve, J.; Débarre, F.; Deforet, M.; Harcombe, W.R.; Peña, J.; Brown, S.P.; Hochberg, M.E. Environmentally Mediated Social Dilemmas. Trends Ecol. Evol. 2019, 34, 6-18. [CrossRef] [PubMed]

6. Andreoni, J. Why Free Ride?: Strategies and Learning in Public Goods Experiments. J. Public Econ. 1988, 37, 291-304. [CrossRef]

7. Van Lange, P.A.M.; Joireman, J.; Parks, C.D.; Van Dijk, E. The Psychology of Social Dilemmas: A Review. Organ. Behav. Hum. Decis. Process. 2013, 120, 125-141. [CrossRef]

8. Iwai, T.; De Azevedo, P.F. Economic Incentives or Communication: How Different Are Their Effects on Trust. BAR-Braz. Adm. Rev. 2016, 13, 1-25. [CrossRef]

9. Messick, D.M.; Wilke, H.; Brewer, M.B.; Kramer, R.M.; Zemke, P.E.; Lui, L. Individual Adaptations and Structural Change as Solutions to Social Dilemmas. J. Pers. Soc. Psychol. 1983, 44, 294-309. [CrossRef]

10. Rapoport, A.; Eshed-Levy, D. Provision of Step-Level Public Goods: Effects of Greed and Fear of Being Gypped. Organ. Behav. Hum. Decis. Process. 1989, 44, 325-344. [CrossRef]

11. Park, G.; DeShon, R.P. Effects of Group-Discussion Integrative Complexity on Intergroup Relations in a Social Dilemma. Organ. Behav. Hum. Decis. Process. 2018, 146, 62-75. [CrossRef]

12. Ferraz Meyer, L.F.; Braga, M.J. Fear or Greed? Duty or Solidarity? Motivations and Stages of Moral Reasoning. Rev. Radic. Polit. Econ. 2015, 47, 159-175. [CrossRef]

13. Fehr, E.; Gächter, S. Altruistic Punishment in Humans. Nature 2002, 415, 137-140. [CrossRef] [PubMed]

14. Fehr, E.; Fischbacher, U. Social Norms and Human Cooperation. Trends Cogn. Sci. 2004, 185-190. [CrossRef]

15. De Quervain, D.J.F.; Fischbacher, U.; Treyer, V.; Schellhammer, M.; Schnyder, U.; Buck, A.; Fehr, E. The Neural Basis of Altruistic Punishment. Science 2004, 305, 1254-1258. [CrossRef]

16. Wang, Q.; Meng, H.; Gao, B. Spontaneous Punishment Promotes Cooperation in Public Good Game. Chaos Solitons Fractals 2019, 120, 183-187. [CrossRef]

17. Dreber, A.; Rand, D.G.; Fudenberg, D.; Nowak, M.A. Winners Don't Punish. Nature 2008, 452, $348-351$. [CrossRef] [PubMed]

18. Mulder, L.B.; van Dijk, E.; De Cremer, D.; Wilke, H.A.M. Undermining Trust and Cooperation: The Paradox of Sanctioning Systems in Social Dilemmas. J. Exp. Soc. Psychol. 2006, 42, 147-162. [CrossRef] 
19. Deci, E.L.; Koestner, R.; Ryan, R.M. A Meta-Analytic Review of Experiments Examining the Effects of Extrinsic Rewards on Intrinsic Motivation. Psychol. Bull. 1999, 125, 627-668. [CrossRef] [PubMed]

20. Herrmann, B.; Thöni, C.; Gächter, S. Antisocial Punishment across Societies. Science 2008, 319, $1362-1367$. [CrossRef]

21. Pleasant, A.; Barclay, P. Why Hate the Good Guy? Antisocial Punishment of High Cooperators Is Greater When People Compete To Be Chosen. Psychol. Sci. 2018, 29, 868-876. [CrossRef]

22. Kollock, P. Social Dilemmas: The Anatomy of Cooperation. Annu. Rev. Sociol. 1998, 24, 183-214. [CrossRef]

23. Weber, J.M.; Murnighan, J.K. Suckers or Saviors? Consistent Contributors in Social Dilemmas. J. Pers. Soc. Psychol. 2008, 95, 1340-1353. [CrossRef]

24. Gill, M.J.; Packer, D.J.; Van Bavel, J. More to Morality than Mutualism: Consistent Contributors Exist and They Can Inspire Costly Generosity in Others. Behav. Brain Sci. 2013, 36, 90. [CrossRef]

25. Gill, M.J.; Packer, D.J.; Chu, K.; Van Bavel, J. Consistent Contributors Can Inspire Robust, Costly Generosity in Those with Altruistic Values. In Proceedings of the 15th International Conference on Social Dilemmas, ETH Zurich, Switzerland, 10-13 July 2013.

26. Harris, N.; Shealy, T.; Klotz, L. How Exposure to "Role Model" Projects Can Lead to Decisions for More Sustainable Infrastructure. Sustainability 2016, 8, 130. [CrossRef]

27. Fowler, J.H.; Christakis, N.A. Cooperative Behavior Cascades in Human Social Networks. Proc. Natl. Acad. Sci. USA 2010, 107, 5334-5338. [CrossRef]

28. Grant, A.M.; Patil, S.V. Challenging the Norm of Self-Interest: Minority Influence and Transitions to Helping Norms in Work Units. Manag. Rev. 2012, 37, 547-568. [CrossRef]

29. Weber, J.M.; Moore, C. Squires: Key Followers and the Social Facilitation of Charismatic Leadership. Organ. Psychol. Rev. 2014, 4, 199-227. [CrossRef]

30. Biel, A.; Thøgersen, J. Activation of Social Norms in Social Dilemmas: A Review of the Evidence and Reflections on the Implications for Environmental Behaviour. J. Econ. Psychol. 2007, 28, 93-112. [CrossRef]

31. Guido, A.; Robbett, A.; Romaniuc, R. Group Formation and Cooperation in Social Dilemmas: A Survey and Meta-Analytic Evidence. J. Econ. Behav. Organ. 2019, 159, 192-209. [CrossRef]

32. March, J.G. Primer on Decision Making: How Decisions Happen; Simon and Schuster: New York, NY, USA, 1994.

33. Bolinger, A.R.; Klotz, A.C.; Leavitt, K. Contributing from inside the Outer Circle: The Identity-Based Effects of Noncore Role Incumbents on Relational Coordination and Organizational Climate. Acad. Manag. Rev. 2018, 43, 680-703. [CrossRef]

34. Newell, B.R.; McDonald, R.I.; Brewer, M.; Hayes, B.K. The Psychology of Environmental Decisions. Annu. Rev. Environ. Resour. 2014, 39, 443-467. [CrossRef]

35. De Boer, J. A Strawson-Lewis Defence of Social Preferences. Econ. Philos. 2012, 28, 291-310. [CrossRef]

36. Decter-Frain, A.; Vanstone, R.; Frimer, J.A. Why and How Groups Create Moral Heroes. In Handbook of Heroism and Heroic Leadership; Taylor \& Francis: New York, NY, USA, 2016; p. 120.

37. Glöckner, A.; Irlenbusch, B.; Kube, S.; Nicklisch, A.; Normann, H.T. Leading with(out) Sacrifice? A Public-Goods Experiment with a Privileged Player. Econ. Inq. 2011, 49, 591-597. [CrossRef]

38. De Cremer, D. Charismatic Leadership and Cooperation in Social Dilemmas: A Matter of Transforming Motives?1. J. Appl. Soc. Psychol. 2002, 32, 997-1016. [CrossRef]

39. Oc, B.; Bashshur, M.R. Followership, Leadership and Social Influence. Leadersh. Q. 2013, 24, 919-934. [CrossRef]

40. Bandura, A. Social Learning Theory; Prentice-Hall: Englewood Cliffs, NJ, USA, 1977.

41. Tsvetkova, M.; Macy, M.W. The Social Contagion of Generosity. PLoS ONE 2014, 9. [CrossRef] [PubMed]

42. Capraro, V.; Perc, M. Grand Challenges in Social Physics: In Pursuit of Moral Behavior. Front. Phys. 2018, 6, 1-6. [CrossRef]

43. Capraro, V.; Jagfeld, G.; Klein, R.; Mul, M.; van de Pol, I. What's the Right Thing to Do? Increasing Pro-Sociality with Simple Moral Nudges. Ssrn 2017. [CrossRef]

44. Capraro, V.; Rand, D.G. Do the Right Thing: Experimental Evidence That Preferences for Moral Behavior, Rather than Equity or Efficiency per Se, Drive Human Prosociality. Judgm. Decis. Mak. 2018, 13, 99-111. [CrossRef]

45. Capraro, V.; Vanzo, A. The Power of Moral Words: Understanding Framing Effects in Extreme Dictator Games Using Sentiment Analysis and Moral Judgments. arXiv preprint, 2019; arXiv:1901.02314. 
46. Krupka, E.L.; Weber, R.A. Identifying Social Norms Using Coordination Games: Why Does Dictator Game Sharing Vary? J. Eur. Econ. Assoc. 2013, 11, 495-524. [CrossRef]

47. Tappin, B.M.; Capraro, V. Doing Good vs. Avoiding Bad in Prosocial Choice: A Refined Test and Extension of the Morality Preference Hypothesis. J. Exp. Soc. Psychol. 2018, 79, 64-70. [CrossRef]

48. Dal Bó, E.; Dal Bó, P. “Do the Right Thing:" The Effects of Moral Suasion on Cooperation. J. Public Econ. 2014, 117, 28-38. [CrossRef]

49. Rand, D.G.; Kraft-Todd, G.; Gruber, J. The Collective Benefits of Feeling Good and Letting Go: Positive Emotion and (Dis) Inhibition Interact to Predict Cooperative Behavior. PLoS ONE 2015, 10, 1-12. [CrossRef]

50. Levine, E.E.; Barasch, A.; Rand, D.; Berman, J.Z.; Small, D.A. Signaling Emotion and Reason in Cooperation. J. Exp. Psychol. Gen. 2018, 147, 702-719. [CrossRef]

51. Bracht, J.; Regner, T. Moral Emotions and Partnership. J. Econ. Psychol. 2013, 39, 313-326. [CrossRef]

52. Baumeister, R.F.; Vohs, K.D.; DeWall, C.N.; Zhang, L. How Emotion Shapes Behavior: Feedback, Anticipation, and Reflection, Rather Than Direct Causation. Personal. Soc. Psychol. Rev. 2007, 11, 167-203. [CrossRef]

53. Bolino, M.C.; Grant, A.M. The Bright Side of Being Prosocial at Work, and the Dark Side, Too: A Review and Agenda for Research on Other-Oriented Motives, Behavior, and Impact in Organizations. Acad. Manag. Ann. 2016, 10, 599-670. [CrossRef]

54. Haidt, J. The Positive Emotion of Elevation. Prev. Treat. 2000, 3, 1-5. [CrossRef]

55. Silvers, J.A.; Haidt, J. Moral Elevation Can Induce Nursing. Emotion 2008, 8, 291-295. [CrossRef] [PubMed]

56. Ma, X.; Zhao, W.; Luo, R.; Zhou, F.; Geng, Y.; Xu, L.; Gao, Z.; Zheng, X.; Becker, B.; Kendrick, K.M. Sexand Context-Dependent Effects of Oxytocin on Social Sharing. Neuroimage 2018, 183, 62-72. [CrossRef]

57. Declerck, C.H.; Boone, C.; Kiyonari, T. Oxytocin and Cooperation under Conditions of Uncertainty: The Modulating Role of Incentives and Social Information. Horm. Behav. 2010, 57, 368-374. [CrossRef]

58. Bartz, J.; Simeon, D.; Hamilton, H.; Kim, S.; Crystal, S.; Braun, A.; Vicens, V.; Hollander, E. Oxytocin Can Hinder Trust and Cooperation in Borderline Personality Disorder. Soc. Cogn. Affect. Neurosci. 2011, 6, 556-563. [CrossRef]

59. Declerck, C.H.; Boone, C.; Kiyonari, T. The Effect of Oxytocin on Cooperation in a Prisoner's Dilemma Depends on the Social Context and a Person's Social Value Orientation. Soc. Cogn. Affect. Neurosci. 2013, 9, 802-809. [CrossRef] [PubMed]

60. Bartz, J.A.; Zaki, J.; Bolger, N.; Ochsner, K.N. Social Effects of Oxytocin in Humans: Context and Person Matter. Trends Cogn. Sci. 2011, 15, 301-309. [CrossRef]

61. Schnall, S.; Roper, J.; Fessler, D.M.T. Elevation Leads to Altruistic Behavior. Psychol. Sci. 2010, 21, 315-320. [CrossRef] [PubMed]

62. Schnall, S.; Roper, J. Elevation Puts Moral Values into Action. Soc. Psychol. Personal. Sci. 2012, 3, 373-378. [CrossRef]

63. Algoe, S.B.; Haidt, J. Witnessing Excellence in Action: The "other-Praising" Emotions of Elevation, Gratitude, and Admiration. J. Posit. Psychol. 2009, 4, 105-127. [CrossRef]

64. Ding, W.; Shao, Y.; Sun, B.; Xie, R.; Li, W.; Wang, X. How Can Prosocial Behavior Be Motivated? The Different Roles of Moral Judgment, Moral Elevation, and Moral Identity among the Young Chinese. Front. Psychol. 2018, 9, 1-10. [CrossRef]

65. Simpson, B. Sex, Fear, and Greed: A Social Dilemma Analysis of Gender and Cooperation. Soc. Forces 2003, 82, 35-52. [CrossRef]

66. Bogaert, S.; Boone, C.; Declerck, C. Social Value Orientation and Cooperation in Social Dilemmas: A Review and Conceptual Model. Br. J. Soc. Psychol. 2008, 47, 453-480. [CrossRef] [PubMed]

67. Pletzer, J.L.; Balliet, D.; Joireman, J.; Kuhlman, D.M.; Voelpel, S.C.; Van Lange, P.A.M. Social Value Orientation, Expectations, and Cooperation in Social Dilemmas: A Meta-Analysis. Eur. J. Pers. 2018, 32, 62-83. [CrossRef]

68. Epstein, S. The Stability of Confusion: A Reply to Mischel and Peake. Psychol. Rev. 1983, 90, 179-184. [CrossRef]

69. Kenrick, D.T.; Funder, D.C. Profiting from Controversy: Lessons from the Person-Situation Debate. Am. Psychol. 1988, 43, 23-34. [CrossRef]

70. Buss, A.R. The Trait-Situation Controversy and the Concept of Interaction. Personal. Soc. Psychol. Bull. 1977, 3, 196-201. [CrossRef]

71. Milgram, S. Behavioral Study of Obedience. J. Abnorm. Soc. Psychol. 1963, 67, 371-378. [CrossRef] 
72. Block, J. Some Reasons for the Apparent Inconsistency of Personality. Psychol. Bull. 1968, 70, $210-212$. [CrossRef]

73. Cooper, W.H.; Withey, M.J. The Strong Situation Hypothesis. Personal. Soc. Psychol. Rev. 2009, 13, 62-72. [CrossRef]

74. McCormick, B.W.; Guay, R.P.; Colbert, A.E.; Stewart, G.L. Proactive Personality and Proactive Behaviour: Perspectives on Person-Situation Interactions. J. Occup. Organ. Psychol. 2019, 92, 30-51. [CrossRef]

75. Hardy, C.L.; Van Vugt, M. Nice Guys Finish First: The Competitive Altruism Hypothesis. Personal. Soc. Psychol. Bull. 2006, 32, 1402-1413. [CrossRef] [PubMed]

76. McNeish, D.M.; Stapleton, L.M. The Effect of Small Sample Size on Two-Level Model Estimates: A Review and Illustration. Educ. Psychol. Rev. 2016, 28, 295-314. [CrossRef]

77. Stegmueller, D. How Many Countries for Multilevel Modeling? A Comparison of Frequentist and Bayesian Approaches. Am. J. Pol. Sci. 2013, 57, 748-761. [CrossRef]

78. Maas, C.J.M.; Hox, J.J. Robustness Issues in Multilevel Regression Analysis. Stat. Neerl. 2004, 58, $127-137$. [CrossRef]

79. Meuleman, B.; Billiet, J. A Monte Carlo Sample Size Study: How Many Countries Are Needed for Accurate Multilevel SEM? Surv. Res. Methods 2009, 3. [CrossRef]

80. Marks, M.; Croson, R. Alternative Rebate Rules in the Provision of a Threshold Public Good: An Experimental Investigation. J. Public Econ. 1998, 67, 195-220. [CrossRef]

81. Pillutla, M.M.; Chen, X.P. Social Norms and Cooperation in Social Dilemmas: The Effects of Context and Feedback. Organ. Behav. Hum. Decis. Process. 1999, 78, 81-103. [CrossRef] [PubMed]

82. Van Lange, P.A.M.; De Bruin, E.M.N.; Otten, W.; Joireman, J.A. Development of Prosocial, Individualistic, and Competitive Orientations: Theory and Preliminary Evidence. J. Pers. Soc. Psychol. 1997, 73, 733-746. [CrossRef]

83. Van Lange, P.A.; Bekkers, R.; Schuyt, T.N.; Vugt, M.V. From Games to Giving: Social Value Orientation Predicts Donations to Noble Causes. Basic Appl. Soc. Psych. 2007, 29, 375-384. [CrossRef]

84. He, L.; Bian, R.; Che, H. The Effects of the Social Value Orientation and Feedback Formats on Decision Behavior in the Public Goods Dilemma. Psychol. Sci. 2013, 2, 446-452.

85. Haesevoets, T.; Folmer, C.R.; Van Hiel, A. Cooperation in Mixed-Motive Games: The Role of Individual Differences in Selfish and Social Orientation. Eur. J. Pers. 2015, 29, 445-458. [CrossRef]

86. Haidt, J. The Moral Emotions. In Handbook of Affective Sciences; Oxford University Press: Oxford, UK, 2003; pp. 852-870.

87. Aquino, K.; McFerran, B.; Laven, M. Moral Identity and the Experience of Moral Elevation in Response to Acts of Uncommon Goodness. J. Pers. Soc. Psychol. 2011, 100, 703-718. [CrossRef]

88. Ding, W.; Wang, X.; Sun, B.; Li, W. The Structure and Measurement of the Moral Elevation. Adv. Psychol. 2014, 4, 777-787. [CrossRef]

89. Fischbacher, U. Z-Tree: Zurich Toolbox for Ready-Made Economic Experiments. Exp. Econ. 2007, 10, 171-178. [CrossRef]

90. Muthén, L.K.; Muthén, B.O. Mplus User's Guide, 8th ed.; Muthén \& Muthén: Los Angeles, CA, USA, 1998.

91. Preacher, K.J.; Zhang, Z.; Zyphur, M.J. Alternative Methods for Assessing Mediation in Multilevel Data: The Advantages of Multilevel SEM. Struct. Equ. Model. A Multidiscip. J. 2011, 18, 161-182. [CrossRef]

92. Preacher, K.J.; Rucker, D.D.; Hayes, A.F. Addressing Moderated Mediation Hypotheses: Theory, Methods, and Prescriptions. Multivariate Behav. Res. 2007, 42, 185-227. [CrossRef]

93. Preacher, K.J.; Zyphur, M.J.; Zhang, Z. A General Multilevel SEM Framework for Assessing Multilevel Mediation. Psychol. Methods 2010, 15, 209-233. [CrossRef]

94. Baron, R.M.; Kenny, D.A. The Moderator-mediator Variable Distinction in Social Psychological Research: Conceptual, Strategic, and Statistical Considerations. J. Pers. Soc. Psychol. 1986, 51, 1173-1182. [CrossRef]

95. Hayes, A.F. Beyond Baron and Kenny: Statistical Mediation Analysis in the New Millennium. Commun. Monogr. 2009, 76, 408-420. [CrossRef]

96. MacKinnon, D.P.; Lockwood, C.M.; Williams, J. Comparison of Approaches in Estimating Interaction and Quadratic Effects of Latent Variables. Multivariate Behav. Res. 2004, 39, 37-67. [CrossRef]

97. Sobel, M.E. Asymptotic Confidence Intervals for Indirect Effects in Structural Equation Models. Sociol. Methodol. 1982, 13, 290. [CrossRef] 
98. Sobel, M.E. Some New Results on Indirect Effects and Their Standard Errors in Covariance Structure Models. Sociol. Methodol. 1986, 16, 159. [CrossRef]

99. Williams, J.; MacKinnon, D.P. Resampling and Distribution of the Product Methods for Testing Indirect Effects in Complex Models. Struct. Equ. Model. A Multidiscip. J. 2008, 15, 23-51. [CrossRef]

100. Preacher, K.J.; Selig, J.P. Monte Carlo Method for Assessing Multilevel Mediation: An Interactive Tool for Creating Confidence Intervals for Indirect Effects in 1-1-1 Multilevel Models [Computer software]. Available online: http:/ / quantpsy.org/ (accessed on 20 January 2019).

101. Chen, X.; Xu, S.; Fan, J. Empirical Methods in Organization and Management Research, 2nd ed.; Peking University Press: Beijing, China, 2012.

102. Preacher, K.J.; Selig, J.P. Advantages of Monte Carlo Confidence Intervals for Indirect Effects. Commun. Methods Meas. 2012, 6, 77-98. [CrossRef]

103. Bass, B.M. Leadership and Perjbrmance beyond Expectations; Free Press: New York, NY, USA, 1985.

104. Shamir, B.; House, R.J.; Arthur, M.B. The Motivational Effects of Charismatic Leadership: A Self-Concept Based Theory. Organ. Sci. 1993, 4, 577-594. [CrossRef]

105. Mas'odl, A.; Sulaiman, Z.; Hashim, N.H.; Khalifah, Z. The Moderating Role of Integrated Persuasive Communication Messages towards Pro-Environmental Behaviour. Soc. Sci. 2016, 11, 4924-4931. [CrossRef]

106. Schultz, P.W.; Nolan, J.M.; Cialdini, R.B.; Goldstein, N.J.; Griskevicius, V. The Constructive, Destructive, and Reconstructive Power of Social Norms: Reprise. Perspect. Psychol. Sci. 2018, 13, 249-254. [CrossRef] [PubMed]

107. McDaniel, W.C.; Sistrunk, F. Management Dilemmas and Decisions. J. Confl. Resolut. 1991, 35, $21-42$. [CrossRef]

108. Poppe, M. The Specificity of Social Dilemma Situations. J. Econ. Psychol. 2005, 26, 431-441. [CrossRef]

109. Poppe, M.; Zwikker, M. The Effect of Threshold Level on Greed, Fear, and Cooperation in Step-Level Give-Some and Take-Some Dilemmas. In Frontiers in Social Dilemmas Research; Springer: Berlin/Heidelberg, Germany, 1996; pp. 185-204.

(C) 2019 by the authors. Licensee MDPI, Basel, Switzerland. This article is an open access article distributed under the terms and conditions of the Creative Commons Attribution (CC BY) license (http:/ / creativecommons.org/licenses/by/4.0/). 